\title{
Produção e Características Qualitativas de Sementes de Plantas Daninhas ${ }^{1}$
}

\author{
Production and Qualitative Characteristics of Weed Seeds
}

SANTOS, J.B. ${ }^{2}$, PROCÓPIO, S.O. ${ }^{3}$, SILVA, A.A. ${ }^{4}$ e COSTA, L.C. ${ }^{5}$

\begin{abstract}
RESUMO - O objetivo deste trabalho foi avaliar a produção (número e peso) e a composição (teores de lipídeo total, proteína total, carboidrato e cinzas) de sementes de Euphorbia heterophylla (biótipos suscetível e resistente aos herbicidas inibidores da ALS), Bidens pilosa e Desmodium tortuosum em condições de campo. Os biótipos de E. heterophylla apresentaram maiores valores para peso de 100 sementes. $D$. tortuosum produziu maior número de sementes por planta $(714,2)$. Para todas as espécies avaliadas, a maior parte da reserva da biomassa seca das sementes foi constituída por carboidrato, e B. pilosa apresentou o maior acúmulo $(61,7 \%)$. Biótipos de $E$. heterophylla acumularam maiores quantidades de lipídeos e de cinzas, enquanto $D$. tortuosum acumulou maior teor de proteínas $(34,8 \%)$. Biótipos de $E$. heterophylla não diferiram quanto a produção e composição de suas sementes.
\end{abstract}

Palavras-chave: Bidens pilosa, Desmodium tortuosum, Euphorbia heterophylla, herbicida, resistência.

ABSTRACT - The objective of this work was to evaluate the production (number and weight) and composition (contents of lipid, protein, carbohydrate and ashes) of Euphorbia heterophylla seeds (susceptible and resistant biotypes to ALS-inhibiting herbicides), Bidens pilosa and Desmodium tortuosum under field conditions. Biotypes of $\boldsymbol{E}$. heterophylla presented the highest weight of 100 seeds. D. tortuosum produced the largest number of seeds per plant (714.25). For all the evaluated species, most of the seed dry biomass reserve was constituted of carbohydrate with B. pilosa presenting the largest accumulation (61.7\%). Biotypes of E. heterophylla accumulated higher amounts of lipids and ashes, while D. tortuosum accumulated higher protein content (34.8\%). Biotypes of E. heterophylla did not differ in their seed production and composition.

Key words: Bidens pilosa, Desmodium tortuosum, Euphorbia heterophylla, herbicide, resistence.

\section{INTRODUÇÃO}

As plantas daninhas, além de competirem com as culturas por água, luz, nutrientes, dióxido de carbono e espaço, podem liberar no solo substâncias químicas que afetam o crescimento e desenvolvimento das culturas (Deuber, 1992). Em determinadas situações, podem ainda hospedar pragas e doenças que atacam as culturas, dificultar ou mesmo impedir a colheita mecânica, prejudicar a qualidade do produto agrícola colhido, além de aumentar os custos de produção (Silva et al., 2000).

A grande habilidade das plantas daninhas de sobreviverem em condições adversas pode ser atribuída à elevada produção, facilidade de dispersão e grande longevidade de suas sementes. De acordo com Santos \& Silva (2000), o número de propágulos produzidos pelas

Recebido para publicação em 8/3/2002 e na forma revisada em 7/8/2002.

2 Acadêmico de Agronomia, Dep. de Fitotecnia da Universidade Federal de Viçosa - UFV, 36571-000 Viçosa-MG, <jbarbosa2000@yahoo.com.br>; ${ }^{3}$ Doutorando, Dep. de Fitotecnia da UFV, <procopio@alunos.ufv.br.>; ${ }^{4}$ Prof. Dep. de Fitotecnia da UFV, <aasilva@mail.ufv.br>; ${ }^{5}$ Prof. Dep. de Engenharia Agrícola da UFV, <l.costa@ mail.ufv.br>. 
plantas daninhas é fator fundamental na maior disseminação e eficiência na competição com culturas. Segundo Lorenzi (2000), as plantas daninhas, geralmente, acumulam nos seus tecidos quantidades muito superiores de nutrientes do que as culturas. O autor afirma também que as plantas daninhas são capazes de utilizá-los de forma mais eficiente.

Em condições climáticas adversas ao desenvolvimento de plantas cultivadas, como o déficit hídrico, normalmente se observam as maiores discrepâncias entre o desenvolvimento das culturas e o das plantas daninhas. São nessas condições em que, com freqüência, as plantas daninhas demonstram sua superioridade competitiva em relação às culturas, mostrando incrivel adaptação à sobrevivência e à reprodução.

Biótipos de Euphorbia heterophylla, resistentes aos herbicidas inibidores de ALS, foram detectados nos Estados do Rio Grande do Sul, Paraná e Mato Grosso do Sul, onde esses produtos são aplicados há vários anos na cultura da soja, sendo essa a principal causa da seleção dos biótipos resistentes (Vargas et al., 1999). Trabalhos mostraram não haver diferença competitiva entre os biótipos sensiveis e resistentes quanto a morfologia, duração de ciclo e potencial de competição com as culturas (Vargas et al., 1999; Vidal \& Trezzi, 2000; Santos \& Silva, 2000).

Desmodium tortuosum é uma planta daninha muito freqüente, principalmente, na Região Centro-Oeste do Brasil. Em razão da sua pouca suscetibilidade a grande parte dos latifolicidas utilizados na cultura da soja, sua infestação vem aumentando nos últimos anos, com sérias ameaças a essa cultura. Segundo Kissmann \& Groth (1992), os maiores prejuízos causados por $D$. tortuosum em lavouras de culturas anuais se devem, principalmente, à sua grande competitividade e à dificuldade que esta planta provoca na colheita mecanizada.

Bidens pilosa está incluída entre as principais espécies daninhas em vários países (Holm et al., 1991). No Brasil, infesta a maioria das culturas anuais e perenes, sendo sua presença quase constante em todas as épocas do ano (Obara et al., 1994). Essa espécie invasora apresenta alta produção de sementes com elevada viabilidade, eficiente mecanismo de dispersão de frutos e, ainda, produção de frutos polimórficos, o que favorece a adaptação a ambientes variados (Tamashiro \& Leitão Filho, 1978).

O objetivo deste trabalho foi avaliar a produção e a composição de sementes das plantas daninhas Euphorbia heterophylla (biótipos sensivel e resistente aos herbicidas inibidores da ALS), Bidens pilosa e Desmodium tortuosum em campo.

\section{MATERIAL E MÉTODOS}

O experimento foi realizado em campo, no período de outubro de 2000 a fevereiro de 2001 , em solo classificado como Argissolo VermelhoAmarelo, fase terraço.

Os tratamentos foram compostos pelas espécies de plantas daninhas Euphorbia heterophylla (resistente a herbicidas inibidores da ALS, coletada no Rio Grande do Sul), Euphorbia heterophylla (sensivel a herbicidas inibidores da ALS, coletada em Minas Gerais), Bidens pilosa e Desmodium tortuosum, totalizando quatro tratamentos. O delineamento experimental utilizado foi o de blocos ao acaso, com duas repetições. As dimensões da parcela experimental foram de 10 metros de largura por 10 metros de comprimento. O espaçamento utilizado foi de 0,6 metro entre linhas, deixando-se cinco plantas por metro.

Os valores de distribuição total das chuvas e condições climáticas, durante o período de avaliação do experimento, são apresentados nas Figuras 1 e 2. Durante a condução do experimento, todos os tratamentos foram mantidos "no limpo" por meio de capinas manuais.

A partir do final do período de enchimento de grãos, foram coletados diariamente todos os propágulos de três plantas, ao acaso, por parcela, sendo eles pesados em balança de precisão, contados, secados em estufa a $75^{\circ} \mathrm{C}$ por 72 horas e encaminhados para as análises dos teores de lipídeo, proteína, carboidrato e cinzas.

A porcentagem de lipídeo foi determinada em aparelho extrator Soxhlet, utilizando éter de petróleo como solvente, segundo o procedimento descrito em Normas Analíticas do Instituto Adolfo Lutz (Instituto Adolfo Lutz, 1985), com refluxo por 24 horas. 


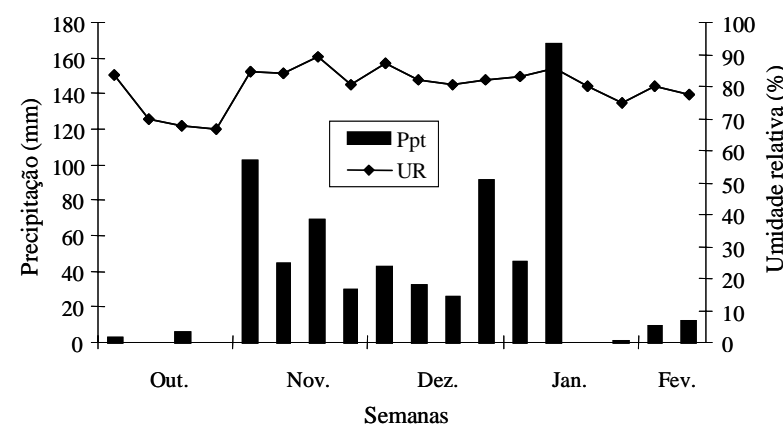

Figura 1 - Médias semanais de precipitação (Ppt) e umidade relativa (UR), no período de outubro de 2000 a fevereiro de 2001.

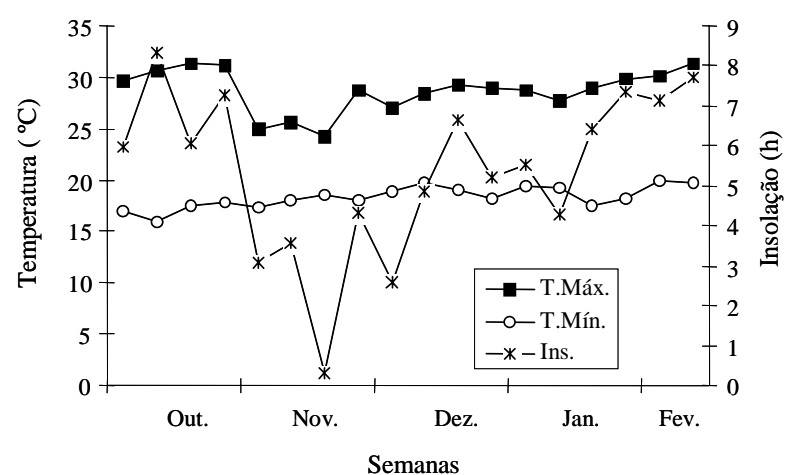

Figura 2 - Médias semanais de temperatura máxima (T. Máx), temperatura mínima (T. Mín.) e insolação (Ins.), no período de outubro de 2000 a fevereiro de 2001.

Realizou-se a determinação de proteínas, segundo o método de Kjeldahl, para a quantificação de nitrogênio total descrito pela Association of Official Analytical Chemists AOAC (1975), com modificações. Na fase de digestão, após obtenção do material aparentemente digerido, adicionou-se peróxido de hidrogênio a 30\%, levando a mistura ao aquecimento por mais 30 minutos. Na fase de destilação, recolheu-se a amônia liberada em solução de ácido bórico a 4\%. Utilizou-se no cálculo da conversão de nitrogênio em proteína o fator de $6,25 \%$.

A fração cinzas foi obtida por meio da calcinação das amostras a $550{ }^{\circ} \mathrm{C}$, conforme o método descrito em Normas Analíticas do Instituto Adolfo Lutz (Instituto Adolfo Lutz, 1985). Por diferença entre o peso total e os teores de lipídeo, proteína e cinzas obteve-se o teor de carboidrato.
Todas as variáveis foram submetidas à análise de variância por meio do teste $\mathrm{F}$, sendo suas médias comparadas pelo teste de Tukey a $5 \%$ de probabilidade.

\section{RESULTADOS E DISCUSSÃO}

Bidens pilosa foi a espécie que produziu o menor peso total de sementes por planta $(1,38 \mathrm{~g})$ (Tabela 1). O maior peso total de sementes por planta foi produzido pelos biótipos de Euphorbia heterophylla (3,72 g), sendo esse peso quase o dobro do encontrado para Desmodium tortuosum $(2,09 \mathrm{~g})$. O peso de 100 sementes observado para D. tortuosum $(0,29 \mathrm{~g})$ foi menor em relação ao valor encontrado para os biótipos de E. heterophylla $(0,76$ e $0,78 \mathrm{~g}$, respectivamente para o biótipo resistente e o sensível), porém foi maior do que o encontrado para B. pilosa $(0,20$ g) (Tabela 1). B. pilosa produziu em média 687,10 sementes por planta, representando, aproximadamente, $50 \%$ a mais em relação ao número de sementes formadas pelos biótipos de $E$. heterophylla $(488,25$ e 478,80 para resistente e sensivel, respectivamente) (Tabela 1). No entanto, o número médio de sementes encontrado para B. pilosa foi menor do que o observado para $D$. tortuosum $(714,25)$. Segundo Kissmann \& Groth (1992), uma planta de $B$. pilosa pode produzir até 3.000 sementes, geralmente de pronta viabilidade.

$\mathrm{Na}$ caracterização das frações que compõem as sementes, verificou-se que em todas as espécies avaliadas a maior parte da reserva da biomassa seca era constituída por carboidrato. B. pilosa obteve o maior teor de carboidrato em suas sementes $(61,78 \%)$ (Tabela 2$)$. D. tortuosum, apesar de ter concentrado menor teor de carboidrato em suas sementes (55,80\%), comparado a B. pilosa, apresentou valor superior ao encontrado para ambos os biótipos de E. heterophylla $(48,46$ e $47,00 \%$ para resistente e sensivel, respectivamente).

Os biótipos de E. heterophylla apresentaram os maiores valores para lipídeo total em suas sementes $(21,04$ e $20,86 \%$ para resistente e sensível, respectivamente), não havendo diferença significativa entre eles (Tabela 2). O teor de lipídeo encontrado nas sementes dos biótipos de $E$. heterophylla difere do encontrado por Suda \& Giorgini (1997), que, ao analisarem a composição da reserva de sementes de 
E. heterophylla, observaram que o principal material constituinte era o lipídeo, representando cerca de $55 \%$ da biomassa seca da semente. B. pilosa produziu, em suas sementes, $12,84 \%$ de lipídeo, sendo esse valor maior que o constatado para D. tortuosum $(5,36 \%)$ (Tabela 2).

O baixo teor de lipídeo constatado nas sementes de D. tortuosum, comparada às outras espécies avaliadas, é compensado pelo elevado teor de proteína encontrado em suas sementes $(34,81 \%)$, valor esse superior ao encontrado para os biótipos de E. heterophylla $(25,35$ e $26,78 \%$, respectivamente para resistente e sensivel) (Tabela 2). Entretanto, o teor de proteína das sementes desses biótipos foram maiores que o determinado nas sementes de B. pilosa $(20,61 \%)$. O teor de proteínas observado para os biótipos de E. heterophylla está de acordo com o encontrado por Suda \& Giorgini (1997), os quais verificaram teor de proteína em sementes de $E$. heterophylla de, aproximadamente, $25 \%$. O teor de cinzas foi maior nas sementes de E. heterophylla (5,15 e $5,37 \%$ para o biótipo resistente e o sensivel, respectivamente). Todavia, o teor de cinzas das sementes do biótipo resistente de E. heterophylla não diferiu significativamente do valor encontrado para B. pilosa $(4,77 \%)$. O menor teor de cinzas foi detectado nas sementes de D. tortuosum (4,01\%) (Tabela 2).

Não foram observadas variações entre os biótipos de $E$. heterophylla (sensivel e resistente aos herbicidas inibidores da ALS) para nenhuma das frações avaliadas nas sementes.

Considerando os dados observados e sabendo que há maior consumo de ATP na formação de lipídeos e de proteínas em relação à produção de carboidratos, pode-se supor que $B$. pilosa tende a apresentar menor gasto energético no período de enchimento de grãos, o que pode representar maior eficiência na

Tabela 1 - Peso total de sementes por planta, peso de 100 sementes e número total de sementes produzidas pelas plantas daninhas Euphorbia heterophylla, Bidens pilosa e Desmodium tortuosum. Viçosa-MG. 2001

\begin{tabular}{|l|c|c|c|}
\hline \multicolumn{1}{|c|}{ Espécie vegetal } & $\begin{array}{c}\text { Peso total de sementes por } \\
\text { planta }(\mathrm{g})\end{array}$ & $\begin{array}{c}\text { Peso de } 100 \text { sementes } \\
(\mathrm{g})\end{array}$ & $\begin{array}{c}\text { Número de sementes } \\
\text { produzidas por planta }\end{array}$ \\
\hline Euphorbia heterophylla (resistente*) $^{*}$ & $3,72 \mathrm{a}$ & $0,76 \mathrm{a}$ & $488,25 \mathrm{~b}$ \\
Euphorbia heterophylla $\left(\right.$ sensível*) $_{\text {Bidens pilosa }{ }^{1 /}}$ & $3,72 \mathrm{a}$ & $0,78 \mathrm{a}$ & $478,80 \mathrm{~b}$ \\
Desmodium tortuosum & $1,38 \mathrm{c}$ & $0,20 \mathrm{c}$ & $687,10 \mathrm{a}$ \\
\hline
\end{tabular}

* Biótipo resistente e sensível aos herbicidas inibidores da ALS. ${ }^{1 /}$ Fruto tipo aquênio.

Médias seguidas de mesma letra na coluna não diferem pelo teste de Tukey a 5\% de probabilidade.

Tabela 2 - Valores percentuais para lipídeo, proteína, carboidrato e cinzas encontrados nas sementes das espécies Euphorbia heterophylla, Bidens pilosa e Desmodium tortuosum. Viçosa-MG. 2001

\begin{tabular}{|c|c|c|c|c|}
\hline \multirow{2}{*}{ Espécie vegetal } & Carboidrato & Lipídeo & Proteína & Cinza \\
\hline & \multicolumn{4}{|c|}{ Fração na sementes (\%) } \\
\hline Euphorbia heterophylla (resistente*) & $48,46 \mathrm{c}$ & $21,04 \mathrm{a}$ & $25,35 \mathrm{~b}$ & $5,15 \mathrm{ab}$ \\
\hline Euphorbia heterophylla (sensível*) & $47,00 \mathrm{c}$ & $20,86 \mathrm{a}$ & $26,78 \mathrm{~b}$ & $5,37 \mathrm{a}$ \\
\hline Bidens pilosa ${ }^{\underline{1}}$ & $61,78 \mathrm{a}$ & $12,84 \mathrm{~b}$ & $20,61 \mathrm{c}$ & $4,77 \mathrm{~b}$ \\
\hline Desmodium tortuosum & $55,80 \mathrm{~b}$ & $5,36 \mathrm{c}$ & $34,81 \mathrm{a}$ & $4,01 \mathrm{c}$ \\
\hline
\end{tabular}

* Biótipo resistente e sensível aos herbicidas inibidores da ALS. ${ }^{1 /}$ Fruto tipo aquênio.

Médias seguidas de mesma letra na coluna não diferem pelo teste de Tukey a 5\% de probabilidade. 
formação de biomassa seca em comparação a E. heterophylla e D. tortuosum nesse período.

\section{AGRADECIMENTOS}

À empresa Syngenta e ao CNPq, pelo apoio financeiro.

\section{LITERATURA CITADA}

ASSOCIATION OF OFFICIAL ANALYTICAL CHEMISTS - AOAC. Official methods of analysis. Washington, D.C.: 1975. $1.094 \mathrm{p}$.

DEUBER, R. Ciência das plantas daninhas: fundamentos. Jaboticabal: Fundação de Estudos e Pesquisas em Agronomia, Medicina Veterinária e Zootecnia, 1992. v. 1, $431 \mathrm{p}$.

HOLM, L. R. G.; PLUCKNETT, D. L.; PANCHO, J. V. The world's worst weeds: distribution and biology. Honolulu: East West Food Institute, 1991. 190 p.

INSTITUTO ADOLFO LUTZ. Normas analíticas do Instituto Adolfo Lutz; Métodos químicos e físicos para análises de alimentos. 3.ed. São Paulo: 1985. v. 1, 533 p.

KISSMANN, K. G.; GROTH, D. Plantas infestantes e nocivas. São Paulo: BASF Brasileira, 1992. 798 p.

LORENZI, H. Plantas daninhas do Brasil. 3.ed. Nova Odessa: Instituto Plantarum, 2000. 608 p.
OBARA, S. Y.; BEZUTTE, A. J.; ALVES, P. L. C. A. Desenvolvimento e composição mineral do picão-preto sob diferentes níveis de pH. Planta Daninha, v. 12, p. 52-56, 1994.

SANTOS, J. B.; SILVA, A. A. Resistência de genótipos de Euphorbia heterophylla $\mathrm{L}$. a herbicidas inibidores da enzima acetolactato sintase (ALS). Viçosa, MG:

Universidade Federal de Viçosa, 2000. 37 p. (Relatório. $\mathrm{PIBIC/CNPq)}$

SILVA, A. A. et al. Controle de plantas daninhas, módulo 3. Brasília, DF: ABEAS, 2000. 260 p.

SUDA, C. N. K.; GIORGINI, J. F. Composição e mobilização de reservas da semente e ocorrência de celulase no endosperma de Euphorbia heterophylla $\mathbf{L}$. (amendoim-bravo). Ribeirão Preto: Faculdade de Medicina de Ribeirão Preto, 1997. 129 p. Dissertação (Mestrado em Bioquímica e Farmácia) - Faculdade de Medicina de Ribeirão Preto, 1997.

TAMASHIRO, S. Y.; LEITÃO FILHO, H. F. Observações sobre o ciclo de vida de Bidens pilosa (Compositae, Helianthae). Hoehnea, v. 7, p. 27-40, 1978.

VARGAS, L. et al. Resistência de plantas daninhas a herbicidas. Viçosa, MG: Edição dos Autores, 1999. 131 p.

VIDAL, R. A.; TREZZI, M. M. Análise de crescimento de biótipos de leiteira (Euphorbia heterophylla) resistentes e susceptível aos herbicidas inibidores da ALS. Planta Daninha, v. 18, p. 427-433, 2000. 